\title{
DESAIN MEDIA INFORMASI PT. PLN (PERSERO) DISTRIBUSI BANTEN
}

\author{
Maimunah $^{1}$ \\ Rifki Adi Syahputra ${ }^{2}$ \\ Dosen Jurusan Teknik Informatika STMIK Raharja ${ }^{1}$ \\ Mahasiswa STMIK Raharja Jurusan Teknik Informatika ${ }^{2}$ \\ Email:maimunah@raharja.info,rifki@raharja.info
}

Diterima: 3 Juli 2018/ Disetujui : 19 Juli 2018

\begin{abstract}
The times growing rapidly very possible, for information on access very easily and obtainable by anyone, anytime and anywhere. From this moment the information becomes very important, and with the information makes it easy for people to get the desired data and information is the message in the form of speech or a facial. Information or communication that is perfect it is that can be digested and accepted easily by the public clearly. The Foundation of the current communication tool delivering the message that we know with communication media. Its function is to simplify, accelerate, in conveying information, resulting in more efficient, effective, and concrete. Communication media lately is very useful for the company, because it can help performance and make an example of creativity in the fields of design, such as banners, billboards and banners which is currently enough demand in the workforce. Background problems that exist today in PT. PLN (Persero) distribution of Banten is a lack of media design information update should be therefore made some design information can be addressed to the public and consumers i.e., design the notice regarding the termination of temporary, Info maintenance, banners to commemorate the Christmas day and new year's, design maintenance Info, as users of electricity, electric bayarlah electric smart, timely, applications and mobile money info PLN. With the graphic design of PT. PLN (Persero) distribution of Banten, may be able to attract people's interest in listening or paying attention to the latest information given to PT. PLN (Persero) Distribution Of Banten.
\end{abstract}

Keywords: information, communication, design.

\begin{abstract}
ABSTRAK
Perkembangan zaman yang kian pesat sangat memungkinkan, untuk informasi di akses dengan sangat mudah dan didapat oleh siapapun, kapanpun dan dimanapun. Mulai saat ini informasi menjadi sangat penting, dan dengan informasi memudahkan orang untuk mendapatkan data yang diinginkan dan informasi merupakan pesan yang berupa ucapan atau mimik muka. Informasi atau komunikasi yang sempurna itu adalah yang dapat dicerna dan diterima dengan mudah oleh masyarakat dengan jelas. Komunikasi saat ini dijadikan alat penyampaian pesan yang kita kenal dengan media komunikasi. Fungsinya adalah untuk mempermudah, mempercepat, dalam menyampaikan informasi, sehingga lebih efisien, efektif, dan konkrit. Media komunikasi belakangan ini sangat bermanfaat sekali bagi perusahaan, karena dapat membantu kinerja dan membuat sebuah kreatifitas contohnya di bidang desain, seperti banner, baliho dan spanduk yang saat ini cukup diminati dalam dunia kerja. Latar belakang permasalahan yang ada saat ini di PT.PLN (Persero) Distribusi Banten adalah kurangnya media desain informasi yang update oleh karenanya harus di buat beberapa desain informasi yang bisa di tujukan kepada masyarakat dan konsumen yakni desain surat pemberitahuan mengenai pemutusan sementara, info pemeliharaan, spanduk untuk memperingati Hari Natal dan Tahun Baru, desain Info pemeliharaan, sebagai pengguna listrik, bayarlah listrik tepat waktu, listrik pintar,
\end{abstract}


aplikasi PLN mobile dan info pemeliharan. Dengan adanya desain grafis di PT.PLN (Persero) Distribusi Banten, semoga mampu menarik minat masyarakat dalam menyimak ataupun memperhatikan informasi terbaru yang di berikan PT.PLN (Persero) Distribusi Banten.

Kata kunci: informasi, komunikasi, desain.

\section{PENDAHULUAN}

PT.PLN (Persero) Distribusi Banten ialah salah satu Unit Induk PT.PLN (Persero) yang bertugas mengelola berbagai pendistribusian tenaga listrik ke pelanggan khususnya di wilayah Provinsi Banten. Sebagai unit baru yang terbentuk pada akhir tahun 2015 dari unit pecahan antara PT.PLN (Persero) Distribusi Jawa Barat (Disjabar), PT.PLN (Persero) Distribusi Banten memiliki 7 unit penggerak yang terdiri dari 6 Area dan 1 Area pengatur Distribusi (APD).

Pelayanan untuk pelanggan dilakukan oleh 6 Area yang memiliki 2 pola organisasi, yaitu Area pola 1 merupakan Area yang tidak mempunyai Rayon dan langsung berfungsi sebagai Unit Operasional Distribusi dan Pelayanan, yaitu Area Cikokol, Area Cikupa, Area Serpong, dan Area Teluk Naga (Eks. Disjaya). Sedangkan Area Pola 2 merupakan Area yang memiliki 1 layer organisasi di bawahnya yang bisa di sebut dengan Rayon, dan berfungsi sebagai Unit Operasional yaitu Area Banten Utara dan Area Banten Selatan. Area Banten Utara memiliki 5 Rayon, yaitu Serang, Rayon Cikande, Rayon Cilegon, Rayon Anyer, dan Rayon Prima Krakatau. Area Banten Selatan memiliki 4 Rayon, yaitu Rayon Rangkasbitung, Rayon Pandeglang, Rayon Labuan, dan Rayong Malingping (Eks. Disjabar).

Berdasarkan data perusahaan pada bulan Mei 2017, PT.PLN (Persero) Distribusi Banten memiliki pelanggan sebesar 2.785.913 pelanggan, Area Serpong sebanyak 445.411 pelanggan, Area Teluk Naga sebanyak 373.387 pelanggan, Area Cikupa sebanyak 360.473 pelanggan, Area Banten Utara sebanyak 684.966 pelanggan, Area Banten Selatan 612.040 pelanggan.

Saat ini PLN masih sangat jarang melakukan penyebaran informasi kepada masyarakat Indonesia, informasi merupakan masalah yang terjadi di PT.PLN sampai saat ini, karena kurangnya informasi mengakibatkan banyak konsumen PT.PLN tidak mengetahui informasi terkini mengenai PT.PLN. Sehingga di buatlah desain media informasi dan juga promosi untuk PT.PLN dan desain itu nantinya bisa di muat di spanduk, baliho, banner, $x$ banner dan di media sosial semisal Instagram, Facebook dan Twitter.

\section{KAJIAN PUSTAKA}

Informasi merupakan hasil pengolahan data dari satu atau berbagai sumber, yang kemudian diolah, sehingga memberikan nilai, arti, dan manfaat".[1]

Media adalah sarana untuk menyimpan pesan atau informasi kepada public dengan menggunakan berbagai unsur komunikasi grafis seperti teks atau gambar atau foto.’[2]

\section{METODE PENELITIAN}

Dalam melakukan penelitian ini, diterapkan beberapa metode yakni :

1. Metode analisa permasalahan, di dalam metode ini ditentukan topik permasalahan penelitian, yakni melakukan interview kepada atasan divisi hukum dan humas PT. PLN (PERSERO) DIstribusi Banten dan beberapa karyawan yang di tugaskan oleh atasan untuk membantu penelitian ini.

2. Metode pengumpulan data yakni dengan melakukan wawancara kepada atasan bagian hukum dan humas PT. PLN (PERSERO) Distribusi Banten dan beberapa karyawan yang di tugaskan oleh 
atasan untuk membantu penelitian ini serta mengumpulkan data yang di dapat dari PT. PLN (PERSERO) DIstribusi Banten.

3. Analisa Data yakni memilih dan kemudian mengolah data yang telah di kumpulkan berdasarkan hasil wawancara dan dari data yang telah di dapat.

4. Metode analisa perancangan, ialah membuat desain menggunakan software atau aplikasi editing.

5. Konsep design yaitu berisi tentang perencanaan desain, tujuan desain, dan strategi desain.

\section{LITERATURE REVIEW}

1. Penelitian yang di lakukan oleh Pajrin Wurika Sahara pada tahun (2016) dengan judul "Pengembangan Media Desain Komunikasi Visual Sebagai Sarana Penunjang Informasi dan Promosi Pada Hotel Sitamiang 2 Bogor" Penilitan ini di lakukan sehingga dalam mencari informasi akan di dapat dengan mudah diperoleh. Informasi ialah hal yang penting, karena penyebaran informasi dapat di lakukan melalui media cetak ataupun media elektronik, dari media itulah masyarakat dapat memperoleh informasi, sehingga Hotel Sitamiang 2 Bogor memerlukan media komunikasi visual yang dapat menunjang informasi dan promosi yang ditunjukkan kepada calon customer.[3]

2. Penelitian yang dilakukan Maimunah, dkk (2015) yang berjudul "Enriching Merchandise sebagai salah satu Media Promosi Mal Taman Palem" taman palem adalah sebuah mal yang berdiri pada perusahaan PT.Bangun Cipta Karya Perkasa, anak perusahaan dari dari Taman Palem Group dn di naungi oleh Agung Sedayu Group. Dalam memikat seorang konsumen atau masyarakat luas serta mitra kerjanya, Mal Taman Palem membutuhkan berbagai media promosi yaitu berupa merchandise. Fungsi merchandise ialah sebagai sebuah alat untuk menunjang promosi bagi setiap perusahaan, lembaga maupun instansi tertentu yang di gunakan sebagai strategi marketing. Saat ini merchandise yang di miliki Mal Taman Palem masih kurang variatif dan inovatif karena masih berupa keseragaman antara satu desain dengan desain yang lainnya. [4]

3. Penelitian yang dilakukan oleh Adi Kusuma Widyatama (2013) berjudul "Pengembangan Media Komunikasi Visual Sebagai Penunjang Informasi Dan Promosi Bagian Pemasaran Pada Perguruan Tinggi Raharja Semester Genap Ta. 2013/2014”. Media promosi dan informasi yang ada ialah media komunikasi visual yang berbentuk berupa Spanduk, Pamflet, Umbul-umbul, Brosur, Baliho, Banner, Counselling card, design background Desktop, dan lainnya. Yang berfungsi untuk penunjang seperti kegiatan promosi dan informasi yang sudah ada untuk mempromosikan dan memberi informasi perihal kegiatan-kegiatan yang diselenggarakan oleh Perguruan Tinggi Raharja. Oleh karena itu, penulis dapat menuangkannya dalam bentuk Laporan yang berjudul "pengembangan media komunikasi visual sebagai penunjang informasi dan promosi bagian pemasaran pada perguruan tinggi raharja semester genap TA. 2013/2014". Dengan harapan dapat berguna dan mempunyai nilai yang lebih.[5]

4. Penelitian yang dilakukan oleh Dewi Imaniar Desrianti, dkk (2014), yang berjudul "Enriching Media Merchandise Sarana Penunjang Promosi Studi Kasus Pada Book Store". Perihal bisnis retail, tidak lepas dari pentingnya pelayanan kepada konsumen dan kualitas barang yang baik. Tetapi pada masa ini seiring dengan ketatnya persaingan dalam dunia bisnis, pelayanan dan kualitas barang tidaklah cukup untuk bias meningkatkan pendapatan dan menjaring konsumen yang loyal. Semua ini membuat para pelaku perusahaan berpikir dan mencari cara untuk bisa bertahan dan stabil dalam bisnisnya. Salah satunya dengan menggunakan media promosi dalam hal ini lebih ke arah media cetak atau media visual yang secara tidak langsung nilai efektifitasnya terasa dalam mengkomunikasikan program-program pemasaran.[6]

5. Penelitian yang dilakukan oleh Faisal Aditya (2015), dari Perguruan Tinggi Raharja yang berjudul "Laporan Kuliah Kerja Praktek Pada Bagian Desain Promosi Di SMK At-Thahirin 2 Ciledug Tangerang". Pada dasarnya kemajuan di bidang teknologi terlebih lagi di dalam multimedia makin hari semakin meningkat, tetapi saat ini sumber daya manusia dibidang multimedia audio visual and broadcasting belum terpenuhi. Oleh karena itu untuk menguasai dan memahami teknologi komputer secara optimal perlu diadakannya Kuliah Kerja Praktek yang diharapkan memberikan dampak yang positif bagi penyelesaian masalah di atas.[7] 


\section{HASIL DAN PEMBAHASAN}

Dalam penelitian ini, telah dibuat beberapa design yang di gunakan sebagai sarana pengenalan komunikasi, serta informasi dan promosi di PT. PLN (PERSERO) Distribusi Banten kepada masyarakat, kosumen, dan partner kerja. Beberapa desain yang di hasilkan di tujukan kepada masyarakat dan konsumen yakni desain surat pemberitahuan mengenai pemutusan sementara, info pemeliharaan, spanduk untuk memperingati Hari Natal dan Tahun Baru, desain Info pemeliharaan, sebagai pengguna listrik, bayarlah listrik tepat waktu, listrik pintar, aplikasi PLN mobile dan info pemeliharan. Nantinya desain ini akan di publish di koran, untuk karyawan yakni PT. PLN (PERSERO) Distribusi Banten desain Kartu Event Crew PLN. Dan untuk Rekan kerja PT. PLN (PERSERO) Distribusi Banten yaitu desain Rubrik, dan sebagainya. Dalam membuat desain digunakan aplikasi Adobe Illustrator CS6.

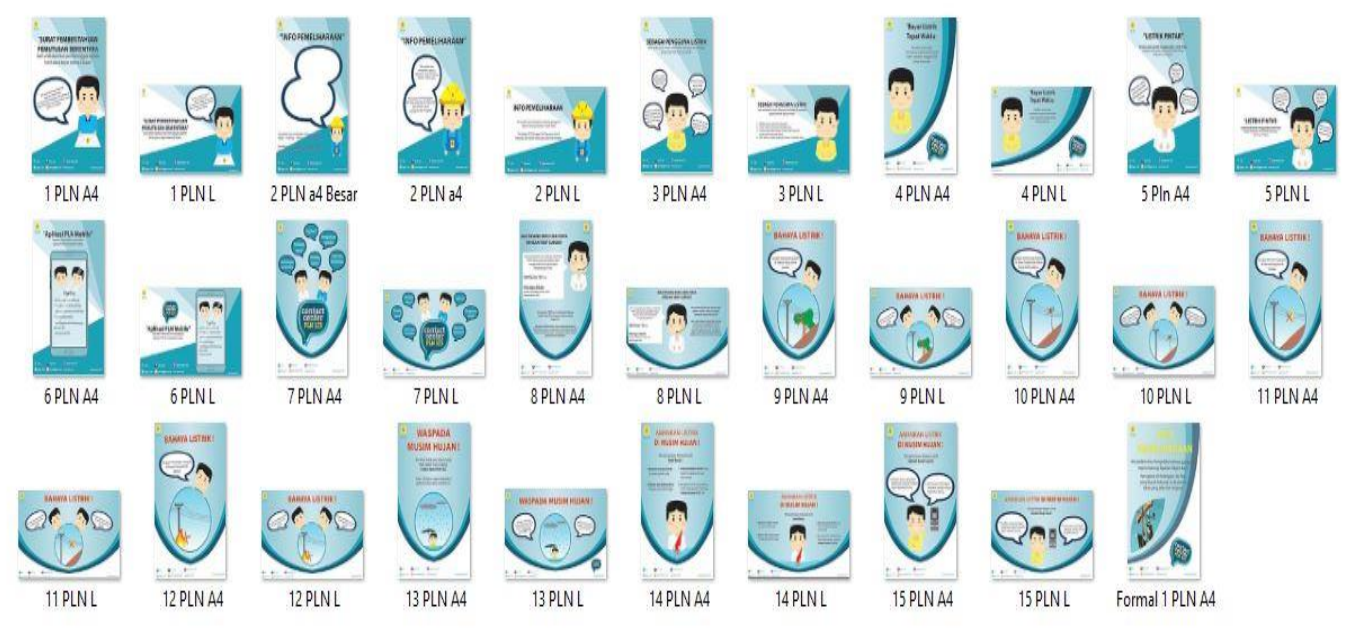

Gambar 1. Kumpulan Informasi

Gambar 1 merupakan kumpulan desain informasi yang di buat menggunakan adobe ilustrator, gambar ini dapat di gunakan untuk di informasikan kepada masyarakat seperti di koran atau media sosial Facebook, Twitter, dan Instagram.

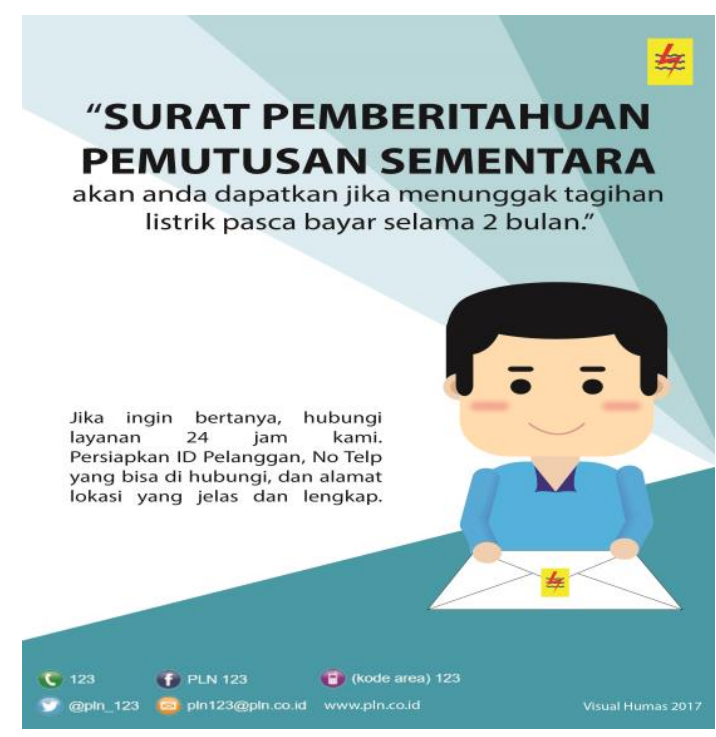

Gambar 2. Surat pemberitahuan pemutusan listrik sementara 
Gambar 2 merupakan design yang menjelaskan perihal surat pemberitahuan pemutusan listrik sementara yang apabila dalam 2 bulan listrik tidak di bayar untuk beritahu kepada masyarakat seperti di koran atau media sosial Instagram, Facebook, dan Twitter.

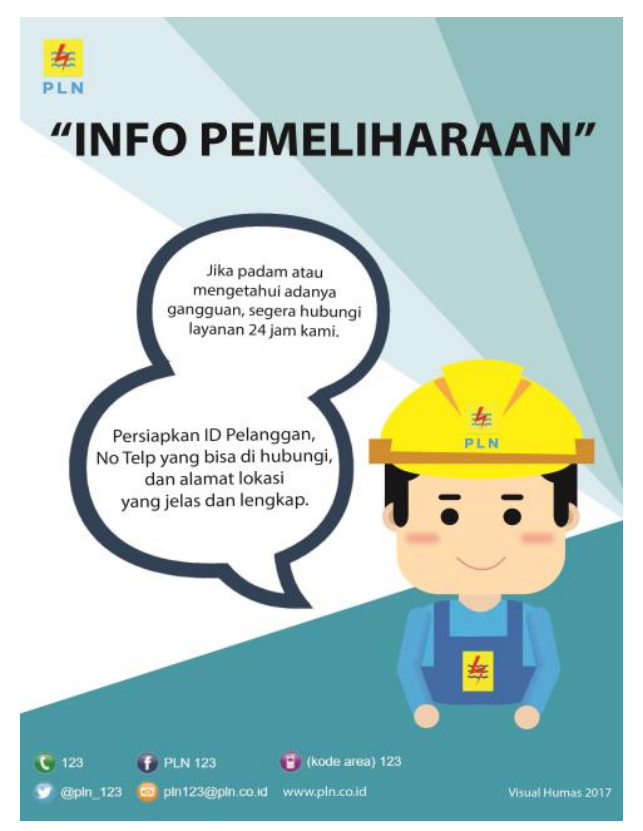

Gambar 3. Info pemadaman atau gangguan listrik

Gambar 3 merupakan design yang menjelaskan apabila sedang terjadi pemadaman atau gangguan listrik di sekitar perumahan anda segera hubungi nomor call center PLN yaitu 123, dan di sebarkan kepada masyarakat seperti di koran atau media sosial Twitter, Facebook, dan Instagram.

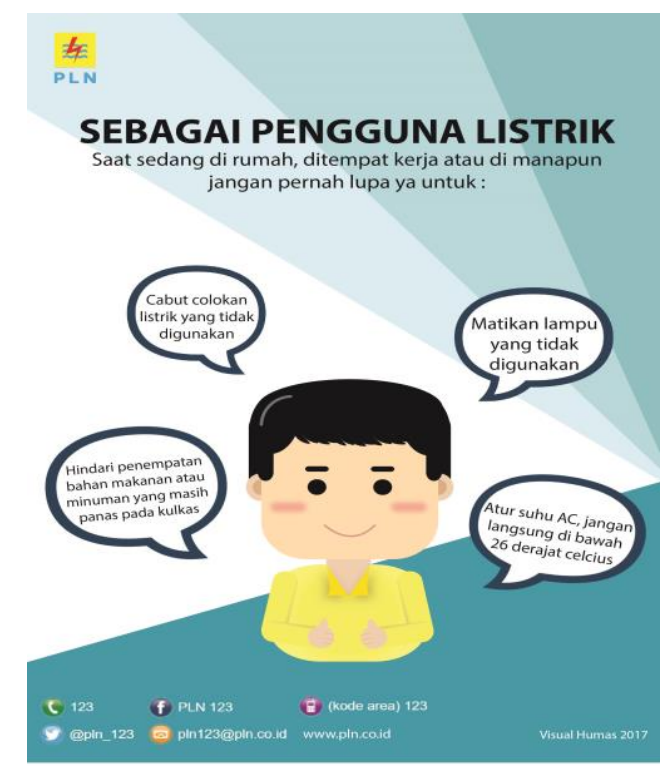

Gambar 4. Informasi penting pengguna listrik

Gambar 4 merupakan design yang mengingatkan semua pengguna listrik untuk tidak lupa mencabut colokan listrik yang sudah tidak di pergunakan lagi, matikan lampu yang tidak di pakai dan atur suhu ac jangan langsung di bawah 26 derajat, dan juga menginformasikan kepada masyarakat seperti di koran atau media sosial Facebook, Instagram, dan Twitter. 


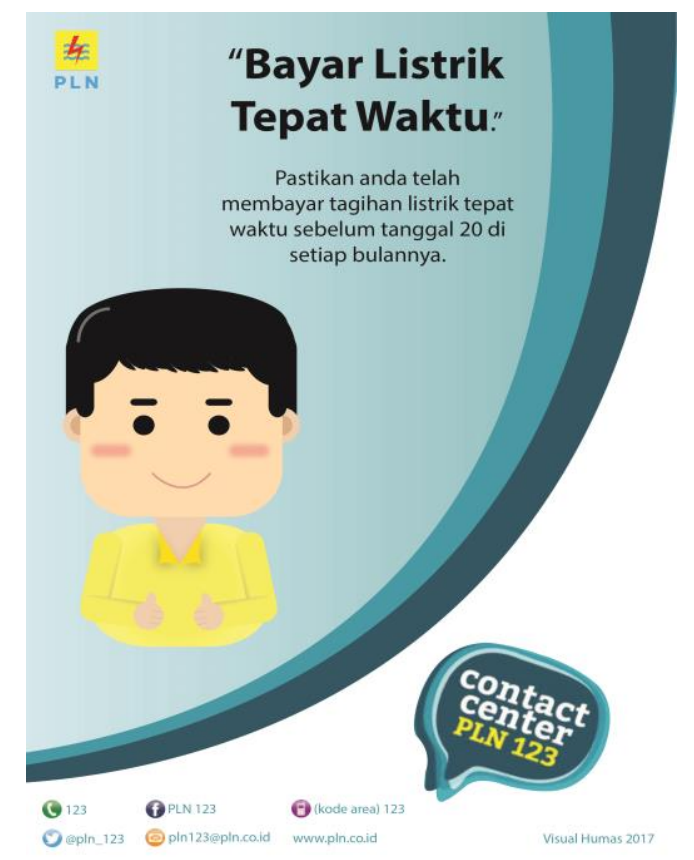

Gambar 5. Himbauan Bayar Listrik tepat waktu

Gambar 5 merupakan design yang menjelaskan atau himbauan untuk bayar listrik tepat waktu agar tidak di terkena denda apabila membyar listrik tidak tepat waktu dan apabila telat 2 bulan membayar listrik, maka akan ada pemutusan listrik untuk sementara waktu

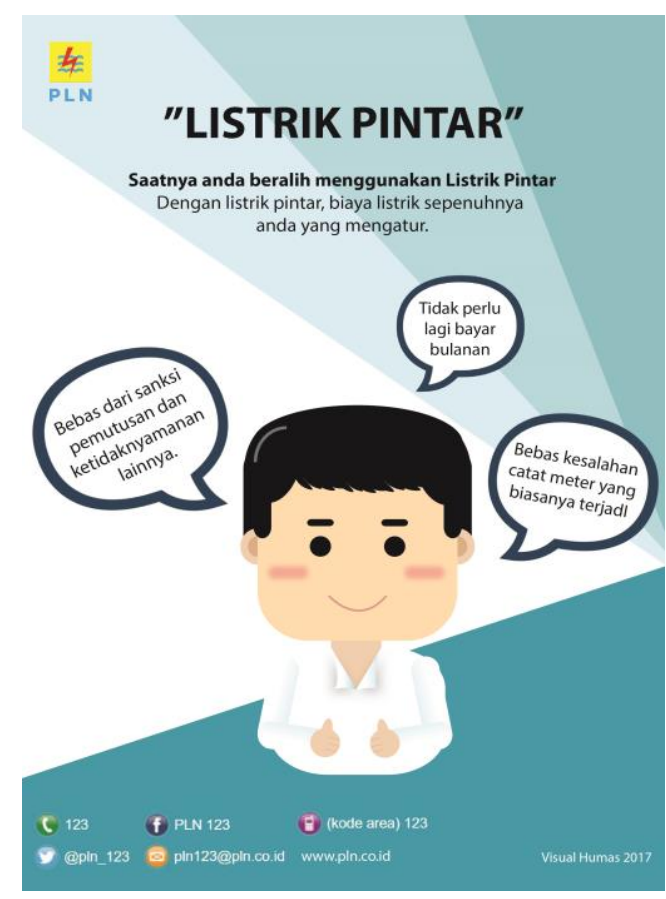

Gambar 6. Listrik Pintar

Gambar 6 merupakan design perihal Listrik Pintar dengan banyak kelebihan semisal konsumen tidak perlu lagi membayar listrik bulanan cukup membeli token listrik apabila token sudah habis, dan bebas dari kesalahan catat meteran yang biasanya sering terjadi 


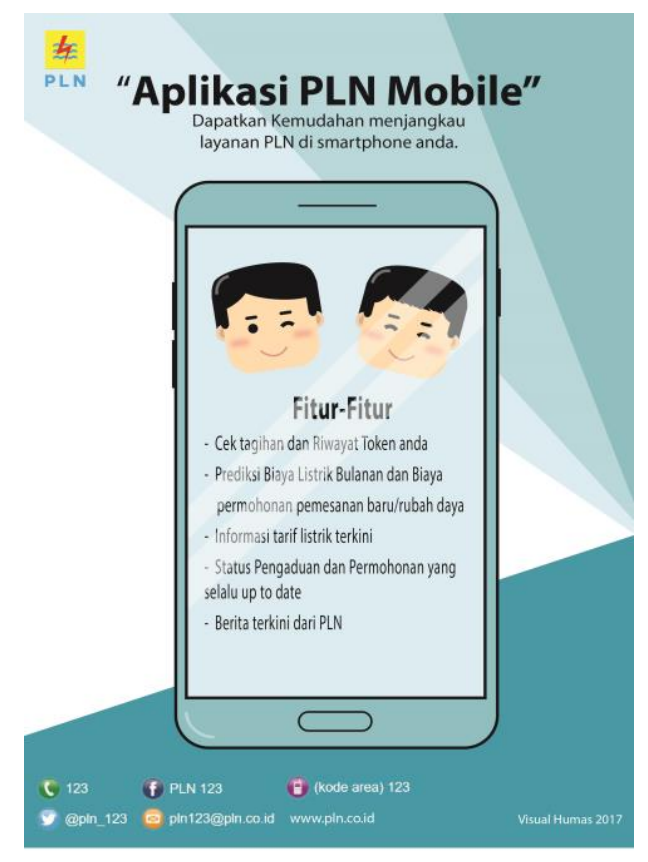

Gambar 7. Aplikasi PLN Mobile

Gambar 7 merupakan design sebuah aplikasi PLN Mobile bertujuan untuk mempromosikan aplikasi PLN berbasis android dimana didalam aplikasi itu terdapat banyak sekali fitur-fitur yang mempermudah anda untuk mengecek tagihan listrik dan juga token anda, prediksi biaya listrik bulanan.

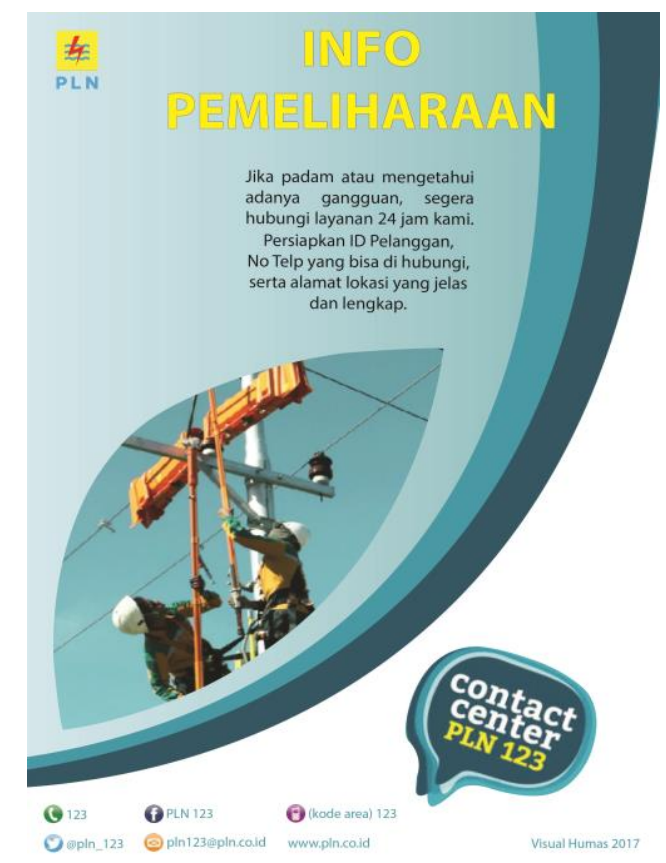

Gambar 8. Info Pemeliharaan

Gambar 8 merupakan design yang mengingatkan mengenai info pemeliharaan, apabila padam diluar jadwal pemeliharaan dapat di pastikan adanya gangguan dan di harapkan melapor, dan gambar ini untuk di publish di koran. 


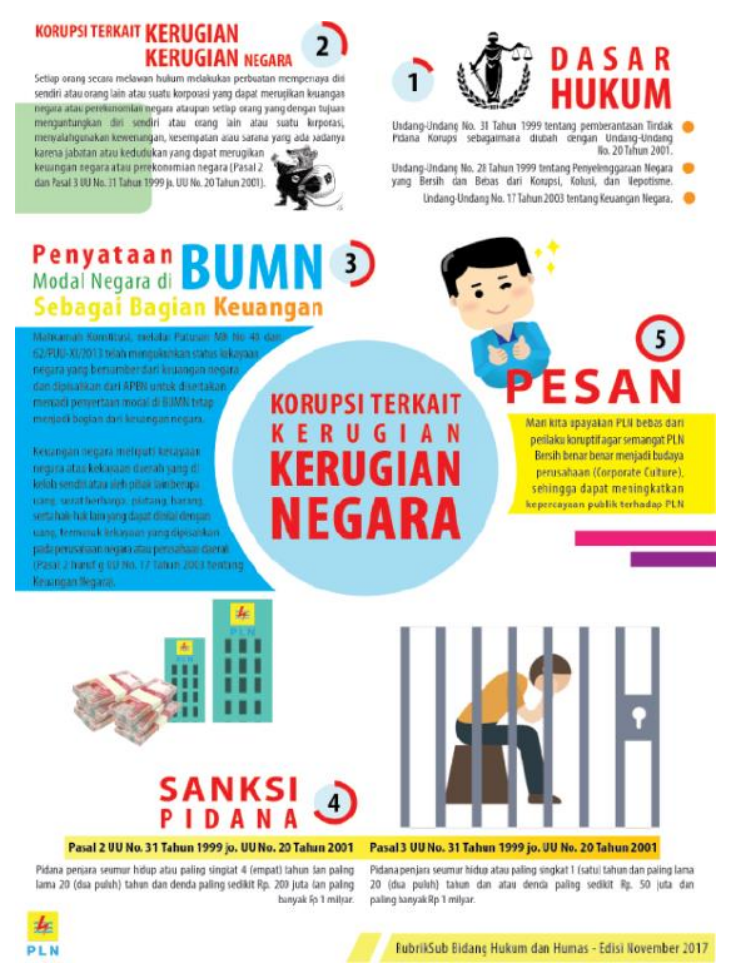

Gambar 9. Rubrik PLN

Gambar 9 merupakan design rubrik yang memaparkan perihal Korupsi terkait kerugian di negara ini, yang berisi dasar hukum beserta pasalnya, kerugian negara, sanksi pidana dan juga pesan agar tidak melakukan korupsi dalam bentuk apapun.

EVENT CREW

\section{Name :}

KERJA NYATA

TERANGI NEGERI

"LISTRIK UNTUK KEHIDUPAN YANG LEBIH BAIK"

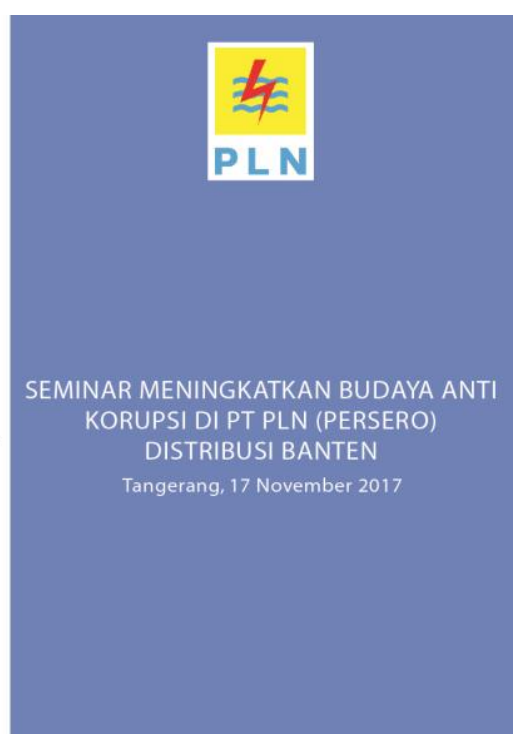

\section{Gambar 10. Kartu Event CREW PLN}

Gambar 10 merupakan design kartu event crew pln. Ini adalah kartu tanda pengenal pegawai PLN sebagai panitia dalam seminar meningkatkan budaya anti korupsi di PT.PLN (Persero) Distribusi Banten. 


\section{KESIMPULAN}

Desain media informasi yang dibuat digunakan untuk memberikan informasi ke masyarakat agar masyarakat mengetahui informasi terbaru dari PT.PLN (Persero) Distribusi Banten. Desain yang dibuat bersifat menarik serta unik agar masyarakat lebih tertarik untuk memperhatikan ataupun menyerap sebuah informasi dengan baik. Dalam membuat desain ini digunakan software Abode Illustrator cs6 sebagai awal untuk membuat sebuah desain media informasi dan software Adobe photoshop cs6 untuk mengcrop atau memotong gambar.

Dalam membuat desain ini juga maka harus perlu memahami dan mempelajari lebih dalam lagi tentang membuat sebuah rancangan media informasi, agar terlihat simple, menarik, menghibur dan isi pesan yang ingin disampaikan tercapai didalam tampilannya, tujuannya agar masyarakat menerima informasi dengan sangat baik, dan semoga desain yang dibuat dapat bermanfaat untuk Masyarakat ataupun PT.PLN (Persero) Distribusi Banten khususnya di Deputi Manajer Humas.

\section{Saran}

Bisa ditambah lagi desain-desain yang bersifat media informasi yang berguna untuk memberikan info terbaru tentang PT.PLN (Persero) Distribusi Banten. Harus konsisten dalam hal memberikan informasi kepada masyarakat atau konsumen pengguna listrik agar tidak ada lagi ketidaktauan masyarakat tentang informasi yang ada di PT.PLN (Persero) Distribusi Banten.

Lebih terbuka lagi dalam memberikan informasi agar masyarakat tidak banyak yang bingung dan kaget dengan adanya informasi yang terbaru, dan juga lebih sering memberikan peringatan atau teguran kepada masyarakat yang telat membayar listrik atau melanggar agar pengguna listrik lebih bijak dalam menggunakan listrik.

\section{Daftar Pustaka}

[1] Pratama, I Putu Agus Eka. 2014. Sistem Informasi dan Implementasinya. Bandung: Informatika.

[2] Maimunah. Lusyani Sunarya. Nina Larasati. 2012. Media Company Profile Sebagai Sarana Penunjang Informasi dan Promosi. Journal CCIT Vol. 5 No. 3. Tangerang: STMIK Raharja.

[3] Sahara, Pajrin Wurika. 2016. Pengembangan Media Desain komunikasi Visual Sebagai Sarana Penunjang Informasi dan Promosi Pada Hotel Sitamiang 2 Bogor. Tangerang : Perguruan Tinggi Raharja.

[4] Maimunah. Lusyani Sunarya. Ferry Sudarto. Raditya Hafidz Mahendra dan Dewi. 2015. Enriching Merchandise Sebagai Salah Satu Media. Tangerang : Perguruan Tinggi Raharja

[5] Widyatama, Adi Kusuma. 2014. Pengembangan Media Komunikasi Visual Sebagai Penunjang Informasi dan Promosi Bagian Pemasaran Pada Perguruan Tinggi Raharja Semester Genap TA. 2013/2014. Tangerang : Perguruan Tinggi Raharja.

[6] Desrianti, Dewi Immaniar, Sudaryono dan Dewi Ayu Ningrum. 2014. Enriching Media Merchandise Sarana Penunjang Promosi Studi Kasus Pada Book Store. Journal CCIT Vol.7 No.3. Tangerang : Perguruan Tinggi Raharja.

[7] Aditya, Faisal. 2015. Laporan Kuliah Kerja Praktek Pada Bagian Desain Promosi di SMK AtThahirin 2 Ciledug Tangerang. Tangerang : Perguruan Tinggi Raharja. 